\title{
LARANGAN RIBA DALAM TEKS DAN KONTEKS (Studi Atas Hadits Riwayat Muslim Tentang Pelaknatan Riba)
}

\author{
Muhammad Tho'in \\ STIE-AAS Surakarta \\ Email: thoinsyakira@yahoo.com
}

\begin{abstract}
Usury is additions which hinted at by people who have treasure to those who borrow their wealth (money) because of postponement payment promise by the borrower of a predetermined time. Usury is divided into two kinds of Nasi'ah usury and Fadhl usury. Threats to the behavior of usury is likened to a drunken man who can not stand but as stands one whom possessed devil because (madness), will be incorporated into the fires of hell and eternal forever, people who do not leave usury will be fought by Allah and His messenger It will be categorized as infidels, get anathema Prophet. Lessons of usury restriction can made man like helping each other, closing the door on the action of disconnecting good relationship fellow men, glorifies work, and do not harm those who are in distress. Allah and the Prophet cursed anyone who involved in such practices without exception. Usury behavioral contexts that society do today which include banking transactions primarily conventional banking, insurance transactions, sale and purchase transactions on credit, and much more.
\end{abstract}

Keywords: Hadith, the prohibition of usury, text and context

\section{PENDAHULUAN}

Hadits merupakan sumber hukum kedua setelah al-Qur'an. Selain fungsi hadits yang gunanya memperkuat apa-apa yang telah diterangkan dalam al-Qur'an juga untuk menerangkan ayat-ayat di dalam al-Qur'an yang masih bersifat umum. Disini peran hadits juga tidak kalah pentingnya dengan al-Qur'an. Apalagi kita sebagai orang yang beriman dan akademisi haruslah mampu mengkombinasikan ilmuilmu sosial atau sains dengan Islam yang diperkuat dalam al-Qur'an dan Hadits agar kecerdasan yang dimiliki tetap berlandaskan pada ketentuan-ketentuan Allah dan Rasul-Nya, sehingga menggunakan kecerdasan tersebut untuk mencari ridho Allah sebagai tujuan utama, bukan mencari harta atau kekayaan sematamata.

Hadits Rasulullah Saw yang terkait dengan praktik-praktik ekonomi sangatlah banyak, baik itu tentang masalah utang piutang, jual-beli, kerja sama, riba dan lain 
sebagainya. Perlunya mengetahui haditshadits yang berkaitan dengan ekonomi ini adalah agar dalam melakukan kegiatan ekonomi kita memiliki pedoman untuk ayat-ayat al-Qur'an yang masih bersifat global.

Riba yang disepakati keharamannya oleh seluruh ulama bahkan oleh seluruh syariat langit, dengan kata lain riba tidak hanya diharamkan oleh agama Islam saja, tetapi agama-agama samawi yang lainpun juga demikian. Allah mengancam orang yang menjalankannya dengan ancaman yang sangat keras. Allah berfirman :

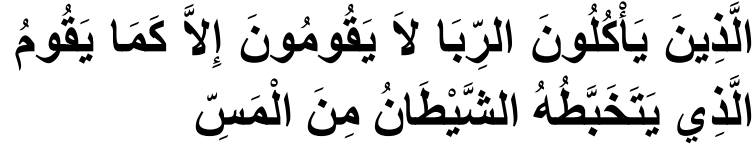

"orang-orang yang makan (mengambil) riba tidak dapat berdiri melainkan seperti berdirinya orang yang kemasukan syaitan lantaran (tekanan) penyakit gila"(Q.S. AlBaqarah: 275).

Ancaman riba yang begitu dahsyat selain dari al-Qur'an, juga terdapat ancaman dari Hadits-hadits Rasulullah. Beliau menjadikan riba sebagai dosa besar yang membinasakan di dunia dan di akhirat. Bahkan semua yang bersinggungan dengan riba semuanya dilaknat oleh Rasulullah Saw. Sebagaimana hadits Rasul sebagai berikut:

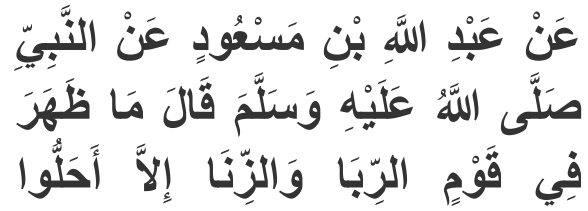

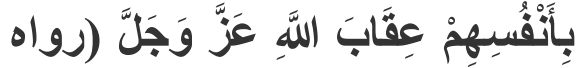

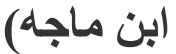

Dari Jabir RA beliau berkata, 'Bahwa Rasulullah SAW melaknat pemakan riba, yang memberikannya, pencatatnya dan saksi-saksinya. Rasulullah SAW mengatakan, 'mereka itu sama.' (HR. Muslim)

Seperti halnya Rasulullah memberitahukan bahwa satu dirham dari riba itu lebih berat dosanya dari tiga puluh tiga kali zina dalam Islam, atau tiga puluh enam zina. Beliau juga memberitahukan bahwa riba itu ada tujuh puluh bab, yang paling rendahnya adalah seperti seseorang menzinai ibunya sendiri.

Di sini muncul pertanyaan: Bagaimana sebenarnya Allah dan Rasulullah Saw melarang dan melaknat perilaku riba (kajian teks dan konteks dalam kegiatan ekonomi)?

Pertanyaan tersebut di atas akan dijawab, dengan terlebih dahulu mengemukakan definisi riba, macammacam riba, ancaman bagi pelaku riba, hikmah pelarangan riba, kemudian hadits tentang Rasulullah Saw melaknat perilaku riba dalam teks dan konteks.

\section{RIBA}

Secara bahasa riba artinya tambahan (ziyadah) atau berarti tumbuh dan membesar. Riba (usury) adalah melebihkan keuntungan (harta) dari salah satu pihak dalam transaksi jual beli atau pertukaran 
barang yang sejenis tanpa memberikan imbalan terhadap kelebihan itu ( riba fadl); atau pembayaran hutang yang harus di lunasi oleh orang yang berhutang lebih besar daripada jumlah pinjamannya sebagai imbalan terhadap tenggang waktu yng telah lewat (riba nasi'ah).

Secara terminologi fiqh: "Tambahan khusus yang dimiliki salah satu dari dua pihak yang terlibat transaksi tanpa ada imbalan tertentu”.

Sedangkan menurut Syaikh Muhammad Abduh bahwa yang dimaksud riba ialah penambahan-penambahan yang di isyaratkan oleh orang yang memiiki harta kepada orang yang meminjam hartanya (uangnya), karena pengunduran janji pembayaran oleh peminjam dari waktu yang telah ditentukan. ${ }^{1}$

\section{MACAM-MACAM RIBA}

Pada umumnya para ulama membagi riba menjadi dua yakni, riba nasi'ah dan riba fadhl.

1. Riba Nasi'ah merupakan tambahan pokok pinjaman yang diisyaratkan dan diambil oleh pemberi pinjaman dari yang berhutang sebagai kompensasi atas tangguhan pinjaman yang diberikannya tersebut. $^{2}$ Allah melarang dan mengharamkan kegiatan demikian, sebagaimana firman Allah Swt dalam

1 Hendi Suhendi, Figh Mu'amalah, Jakarta: Raja Grafindo Persada, 2007, h. 57-58

2 Sayyid Sabiq, Fiqh Sunnah, Cet. ke-1, Jakarta: Tinta Abadi Gemilang, 2013, Jilid 5, h. 107 surah al-Baqarah ayat 280 yang begitu jelas.

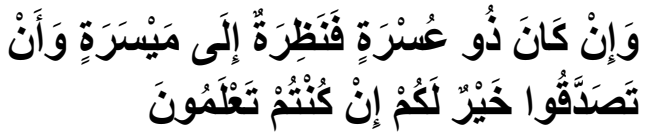

"Dan jika (orang yang berhutang itu) dalam kesukaran, Maka berilah tangguh sampai Dia berkelapangan. dan menyedekahkan (sebagian atau semua utang) itu, lebih baik bagimu, jika kamu mengetahui." (Al-Baqarah : 280). ${ }^{3}$

Dari firman Allah di atas, dapat disimpulkan bahwa jika telah jatuh tempo hutang seseorang tersebut, sedangkan ia masih dalam kesulitan hendaknya orang yang menghutangkan bersasabar dan tidak menagihnya. Sedangkan jika orang yang berhutang telah memiliki, dan dalam keadaan lapang, maka wajib baginya membayar hutangnya tersebut, dan dia tidak perlu menambah nilai dari tanggungan hutang yang dipinjamnya, baik orang yang berutang tersebut sedang memiliki uang atau sedang keadaan sulit. ${ }^{4}$ Bahkan dari ayat tersebut memberikan pelajaran yang luar biasa mengenai mengikhlaskan uang yang kita hutangkan kepada saudara kita, terlebih saudara kita tersebut dalam keadaan kesulitan. Karena Allah akan menggantinya dengan pahala sedekah. 
2. Riba Fadhl, merupakan yang sejenis yang disertai tambahan baik berupa uang maupun berupa makanan. ${ }^{5}$ Istilah dari riba Fadhl diambil dari kata $a l$ - fadhl, yang artinya tambahan dari salah satu jenis barang yang dipertukarkan dalam proses transaksi. Di dalam keharamannya syariat telah menetapkan dalam enam hal terhadap barang ini, yaitu: emas, perak, gandum putih, gandum merah, kurma, dan garam. Jika dari enam jenis barang tersebut ditransaksikan seara sejenis disertai tambahan, maka hukumnya haram. Sebagaimana hadits Rasul Saw:

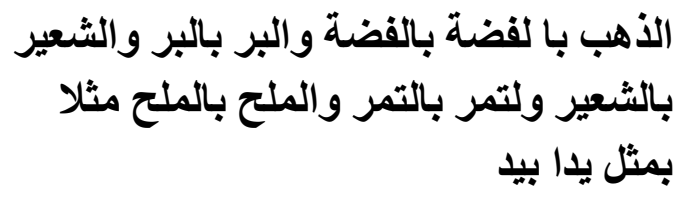

"Emas dengan emas, perak dengan perak, gandum putih dengan gandum putih, gandum merah dengan gandum merah, kurma dengan kurma, (dalam memperjual-belikannya), harus dengan ukuran yang sama, dan diterima secara langsung"(HR Ahmad dan Muslim) ${ }^{6}$

\section{ANCAMAN BAGI PERILAKU RIBA}

Ancaman bagi perilaku riba begitu mengerikan baik dari al-Qur'an maupun hadits nabi, ancaman-ancaman tersebut antara lain:

\footnotetext{
${ }^{5}$ Sayyid Sabiq, Fiqh Sunnah..., h. 107

${ }^{6}$ Saleh Fauzan, Fiqh..., h.391-392
}

1. Mereka yang melakukan tindakan riba tidak bisa berdiri seperti berdirinya orang yang kemasukan syaitan lantaran yang diibaratkan seperti orang sedang mabuk. Kemudian akan Allah masukkan mereka ke dalam neraka yang kekal. Sebagaimana firman Allah surah alBaqarah ayat 275:

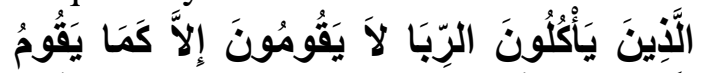

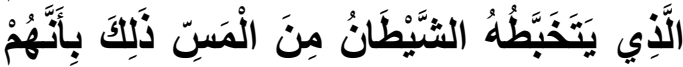

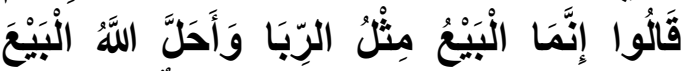

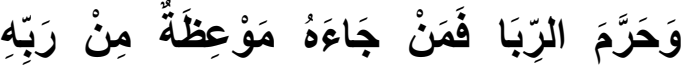

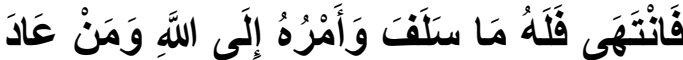

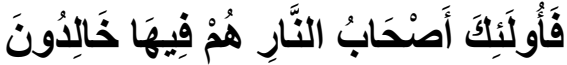

"Orang-orang yang memakan (mengambil) riba, tidak dapat berdiri melainkan seperti berdirinya orang yang kemasukan syaitan lantaran tekanan penyakit gila. Hal itu karena mereka mengatakan, bahwasanya jual beli itu adalah seperti riba. Dan Allah menghalalkan jual beli serta mengharamkan riba. Maka barangsiapa yang telah datang padanya peringatan dari Allah SWT kemudian ia berhenti dari memakan riba, maka baginya apa yang telah diambilnya dahulu dan urusannya terserah kepada Allah. Namun barang siapa yang kembali memakan riba, maka bagi mereka adalah azab neraka dan mereka kekal di dalamnya selama-lamanya”

2. Allah Swt dan Rasulullah Saw akan memerangi mereka, serta mereka dianggap kafir. (QS. 2 : 278 - 279) 


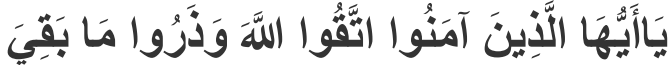

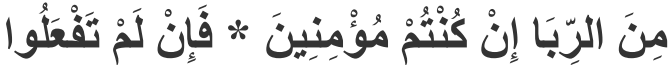

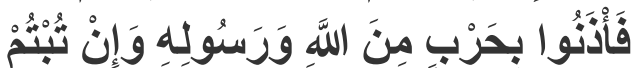

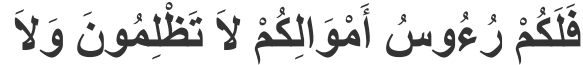 * تُطَنْلَمُونَ "Hai orang-orang yang beriman, bertaqwalah kepada Allah dan tinggalkan sisa riba (yang belum dipungut) jika kamu orang-orang yang beriman. Maka jika kamu tidak mengerjakan (meninggalkan sisa riba), maka ketahuilah, bahwa Allah dan Rasul-Nya akan memerangimu. Dan jika kamu bertaubat (dari pengambilan riba), maka bagimu pokok hartamu; kamu tidak menganiaya dan tidak (pula) dianiaya."}

3. Dilaknat oleh Rasulullah Saw

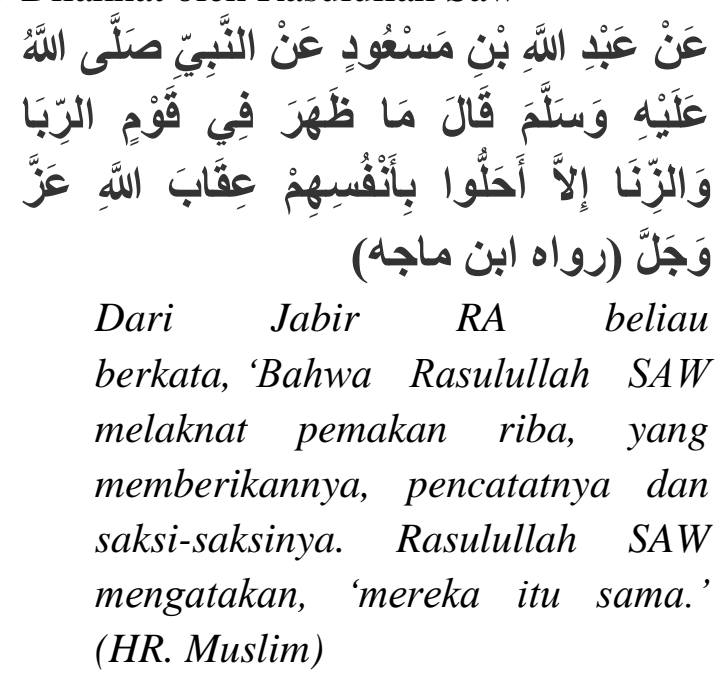

4. Diadzab Allah Saw. Sebagaimana sabda Rasulullah Saw
عَنْ عَبْدِ اللَّهِ بْنِ مَسنعُودٍ عَنْ النَّبَّيَ صَلَّى اللَّهُ

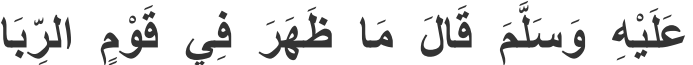

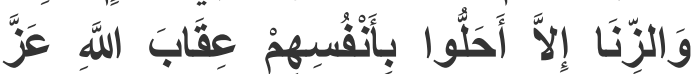

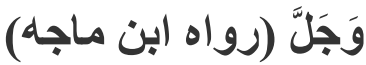

Dari Abdullah bin Mas'ud RA dari Rasulullah SAW beliau berkata, 'Tidaklah suatu kaum menampakkan riba dan zina, melainkan mereka menghalalkan terhadap diri mereka sendiri azab dari Allah SWT. (HR. Ibnu Majah)

5. Dosanya jauh lebih berat dibandingkan orang yang berzina berkali-kali. Sebagaimana sabda Rasulullah Saw

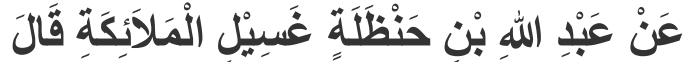

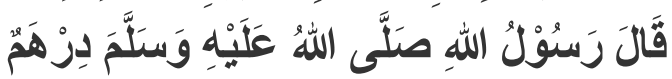

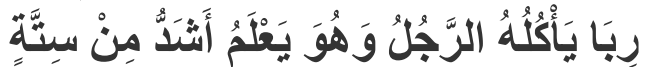

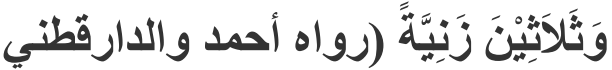
و الطبر اني)

Dari Abdullah bin Handzalah (ghasilul malaikah) berkata, bahwa Rasulullah SAW bersabda, 'Satu dirham riba yang dimakan oleh seseorang dan ia mengetahuinya, maka hal itu lebih berat dari pada tiga puluh enam perzinaan. (HR. Ahmad, Daruquthni dan Thabrani).

\section{HIKMAH PELARANGAN RIBA}

Banyak hikmah yang dapat dipetik dari adanya pelarangan perilaku riba, yang tentunya akan menjadikan manusia jauh 
lebih baik. Beberapa hikmah pelaranggan riba tersebut antara lain :

1. Menjadikan pribadi-pribadi manusia yang suka saling menolong satu sama lain;

2. Dengan sikap saling tolong menolong menciptakan persaudaraan yang semakin kuat. Sehingga menutup pintu pada tindakan memutus hubungan silaturrahmi baik antar sesama manusia; ${ }^{7}$

3. Menjadikan kerja sebagai sebuah kemuliaan, karena pekerjaan tersebut sebagai sarana untuk memperoleh penghasilan. Karena dengan bekerja seseorang dapat meningkatkan keterampilan dan semangat besar dalam hidupnya; ${ }^{8}$

4. Tidak merugikan orang-orang yang sedang kesusahan, karena dengan adanya riba seseorang yang mengalami kesulitan justru semakin susah; dan lain sebagainya.

\section{HADITS PELAKNATAN RIBA DALAM TEKS DAN KONTEKS}

Tidaklah Allah dan Rasul melarang dan melaknat dari sesuatu kecuali karena adanya dampak buruk dan akibat yang tidak baik bagi pelaku. Seperti Allah dan Rasul melarang dari praktek riba, karena berakibat buruk bagi para pelakunya, baik ketika di dunia maupun kelak di akhirat.

1. Teks hadits pelaknatan riba

${ }^{7}$ Saleh Fauzan, Fiqh..., h.390

${ }^{8}$ Sayyid Sabiq, Fiqh Sunnah..., h. 106

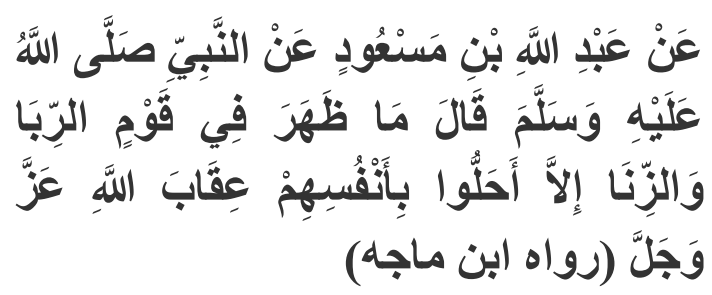

Dari Jabir RA beliau berkata, 'Bahwa Rasulullah SAW melaknat pemakan riba, yang memberikannya, pencatatnya dan saksi-saksinya. Rasulullah SAW mengatakan, 'mereka itu sama.' (HR. Muslim)

Hadits di atas merupakan hadits yang shahih yang disepakati oleh para ulama hadits. Hadits ini diriwayatkan para Imam hadits yang sangat banyak, diantaranya: Imam Muslim dalam Shahihnya, Kitab Al-Musaqat, Bab La'ni Aakilir Riba Wa Mu'kilihi, hadits no 2995. Imam Ahmad bin Hambal ra, dalam Musnadnya, dalam Baqi Musnad Al-Muktsirin, hadits no $137444^{9}$

Selain itu, hadits ini juga memiliki syahid (hadits yang sama yang diriwayatkan melalui jalur sahabat yang berbeda), diantaranya dari jalur sahabat Abdullah bin Mas'ud dan juga dari Ali bin Abi Thalib, yang diriwayatkan oleh: Imam Turmudzi dalam Jami'nya, Kitab Buyu' An Rasulillah, Bab Ma Ja'a Fi Aklir Riba, hadits no 1127. Imam Nasa'I dalam Sunannya, Kitab At-Thalaq, Bab Ihlal Al-Muthallaqah Tsalasan Wan

\footnotetext{
${ }^{9}$ Riska Maulan, Dahsyatnya Riba: Bunga Bank dan Riba, Jakarta: Majelis Ta'lim Wirausaha, 2016
} 
Nikahilladzi Yuhilluha Bihi, Hadits no. 3363. Imam Abu Daud dalam Sunannya, Kitab Al-Buyu', Bab Fi Aklir Riba Wa Mu'kilihi, hadits no. 2895. Imam Ahmad bin Hambal dalam Musnadnya di banyak tempat, diantaranya pada hadits-hadits no 3539, 3550, 3618, 4058, 4059, 4099, 4171 dsb. Imam Ad-Darimi dalam Sunannya, Kitab Al-Buyu', Bab Fi Aklir Riba Wa Mu'kilihi, hadits no 2423. ${ }^{10}$

Makna hadits secara umum di atas, menggambarkan mengenai bahaya dan buruknya riba bagi kehidupan kaum muslimin. Begitu buruk dan bahayanya riba, sehingga digambarkan bahwa Rasululla Saw melarang serta melaknat seluruh pelaku riba. Pemakannya, pemberinya, pencatatnya maupun saksisaksinya. Dan keesemua golongan yang terkait dengan riba tersebut dikatakan oleh Rasulullah SAW; "Mereka semua adalah sama,yaitu sama dosanya."

Pelarangan serta pelaknatan Rasulullah SAW terhadap para pelaku riba menggabarkan betapa munkarnya amaliyah ribawiyah, mengingat Rasulullah Saw tidak pernah melaknat suatu keburukan, melainkan keburukan tersebut membawa kemadharatan yang luar biasa, baik dalam skala indiividu bagi para pelakunya, maupun dalam skala mujtama' atau masyarakat secara luas. Oleh karena itu, setiap muslim wajib menghindarkan dirinya dari praktek riba dalam segenap aspek

\footnotetext{
${ }^{10}$ Maulan, Dahsyatnya Riba...., 2016
}

kehidupannya. Karena jika tidak kehancuran diri dan masyarakat yang akan di dapatkan.

Dalam hadits yang lain Rasulullah juga memberikan penjelasan bahwa riba perilaku yang membinasakan manusia.

Dari Abu Hurairah ra, dari Rasulullah SAW berkata, 'Jauhilah tujuh perkara yang membinasakan !' Para sahabat bertanya, 'Apa saja tujuh perkara tersebut wahai Rasulullah?' Beliau menjawab, 'Menyekutukan Allah, sihir, membunuh jiwa yang diharamkan Allah SWT kecuali dengan jalan yang benar, memakan riba, mamakan harta anak yatim, lari dari medan peperangan dan menuduh berzina pada wanita-wanita mu'min yang sopan yang lalai dari perbuatan jahat. (Muttafaqun Alaih).

2. Konteks hadits pelaknatan riba

Di lembaga keuangan sekarang sebut saja bank banyak terjadi praktek ribawi, walaupun cara pandang ulama mengenai bunga bank konvensional ada yang mengatakan riba, ada pula yang mengatakan tidak. Hal itupun terjadi pada bank syariah yang notabenya adalah lembaga syariah, dimana dalam prakteknya masih jauh dari kata syariah. Bahkan syariah dijadikan bumbu untuk menutupi praktek ribawi. Hal tersebut karena perbankan syariah di Indonesia saat ini masih berlandaskan pada pasar, 
bukan berlandaskan ideologi. Praktek tersebut tidak saja dilakukan oleh lembaga, bahkan orang per orang melakukan pinjaman secara pribadi dengan dasar untuk memperoleh keuntungan berupa tambahan pinjaman.

Dalam konteks lain, di masyarakat masih sering melakukan pertukaran barang atau uang yang sejenis tapi dalam kadar yang berbeda. Misalnya, saat menjelang lebaran ada beberapa orang melakukan usaha tukar uang baru dengan uang lama, tetapi jumlah yang di tukar nilainya berbeda, dan lain-lain.

Dari praktek-praktek riba tersebut, Allah dan Rosul melaknat siapapun yang ikut terlibat di dalam praktek tersebut tanpa kecuali. Sehingga kita perlu waspada di dalam melakukan kegiatan ekonomi sehari-hari.

Secara rinci atau garis besar konteks hadits pelarangan dan pelaknatan riba yang terjadi sehari-hari di masyarakat adalah sebagai berikut:

a. Transaksi perbankan

Sebagaimana kita diketahui bersama, bahwa basis pendekatan atau sistem yang digunakan dalam praktik khususnya perbankan konvensional menggunakan pendekatan berbasis bunga baik dari aspekpenghimpunan maupun penyaluran dananya dari dan untuk masyarakat. Dimana pihak nasabah sebagai peminjam dana bank serta pihak bank bertindak selaku pemberi pinjaman dana tersebut. Atas dasar pinjaman dana tersebut, nasabah akan dikenakan bunga dalam prosentase tertentu atas pinjaman pokok sebagai kompensasi atau imbalan dari pertangguhan waktu atas pembayaran hutang atau pinajaman nasabah tersebut, dimana pihak bank tidak memperdulikan hasil usaha nasabahnya, apakah usaha nasabah tersebut berhasil danberkembang sehingga memperoleh keuntungan atau bahkan mengalami gagal sehingga mengalami kebangkrutan.

Kasus seperti di atas, sebenarnya hampir sama dengan praktik kegiatan riba jahiliyah pada zaman dulu. Tetapi memiliki sedikit perbedaan, riba jahiliyah bungaatau tambahan baru akan dikenakan ketika peminjam tidak mampu membayar atas hutangnya pada waktu yang ditentukan kepada peminjam, sebagai imbalan atas penambahan waktu pembayaran yang mengalamikemunduran. Sedangkan kasus pada praktik perbankan saat ini, besarnya bunga telah ditetapkan dimuka atau pada saat akad kedua belah pihak terjadi. Sehingga dapat disimpulkan sebenarnya praktik riba di perbankkan saat ini jauh lebih jahiliyah di bandingkan dengan riba jahiliyah itu sendiri. Hal itu diakui pula oleh sebagaian besar para ulama.

Jika dari aspek pembiayaan demikian, tidak berbeda pula dalam hal penghimpunan dana, sebut saja 
produk tabungan. Pada saat menabung nasabah dijanjikan terlebih dahulu akan memperoleh bunga yang pasti. Berbeda dengan sistem yang ada pada bank syariah, di mana bank syariah tidak menjanjikan keuntungan tetap, melainkan hanya nisbah bagi hasil keuntungan bukan dari pokok uangnya. Sehingga keuntungan kedua belah pihak tergantung hasilusahanya. Meskipun demikian, ada pula bank syariah yang secara struktur menggunakan sistem bagi hasil tapi kenyataannya secara kultur atau pelaksanaan juga sama bank konvensional hanya beda namanya saja.karena sesungguhnya sampai saat ini saya melihat bahwa bank syariah baru dibangun dari sistem pasar bukan ideologi. Sehingga transaksi perbankan yang dilakukan masyarakat setiap hari sangat rentan terlibat praktik riba yang dilarang dan dilaknat oleh Allah dan Rasul.

b. Transaksi Asuransi

Praktik asuransi yang ada saat ini, masih banyak yang mengandung unsur ribawi. Karena dalam asuransi saat ini, khususnya asuransi konvensional terjadi ketidakseimbangan antara hak dan kewajiban diantara keduanya. Sehingga kecenderungan yang terjadi pihak konsumen sering mengalami kerugian. Sehingga hal-hal yang seharusnya menjadi hak konsumen tidak diberikan. c. Transaksi jual beli secara kredit

Jual beli secara kredit sebenarnya diperbolehkan, hanya saja saat ini yang berkembang adalah jual beli kredit dengan sistem bunga. Apalagi jika sifat dari kredit itu dengan sistem bunga yang berfruktuatif, menjadikan ketidakjelasan. Sehingga harga dari jual dan harga dari belinya menjadi tidak jelas. Sementara dalam syariah Islam sebenarnya jual beli harus ada kepastian antara penjual dan pembeli terkait dengan harga salah satunya, serta tidak diperbolehkan akan adanya perubahan yang tidak pasti, barang maupun harga yang diperjualbelikan tersebut.

Secara kontekstual sesungguhnya transaksi-transaksi yang mengandung unsur ribawi di tengah-tengah kehidupan kita masih banyak lagi. Intinya adalah kita harus waspada dan menghindarkan diri sejauh-jauhnya dari muamalah seperti ini. Agar laknat Allah dan Rasul tidak menimpa kita sebagai individu maupun masyarakat, sehingga terhindar dari azab Allah Swt.

\section{KESIMPULAN}

Dari pembahasan siatas dapat disimpulkan bahwa :

1. Riba ialah penambahan-penambahan yang di isyaratkan oleh orang yang memiki harta kepada orang yang meminjam hartanya (uangnya), karena pengunduran janji pembayaran oleh 
peminjam dari waktu yang telah ditentukan.

2. Riba terbagi dua macam yaitu riba nasi'ah dan riba fadhl.

3. Ancaman terhadap perilaku riba adalah diibaratkan seperti orang mabuk yang tidak bisa berdiri melainkan seperti berdirinya orang yang kemasukan syaitan lantaran (penyakit gila), Akan dimasukkan ke dalam api neraka dan kekal selamanya, orang yang tidak meninggalkan riba akan diperangi oleh Allah dan rasul-Nya serta akan dikategorikan sebagai orang kafir, mendapatkan laknat Rasulullah Saw.

4. Hikmah pelaranggan riba diantaranya menjadikan manusia suka saling tolong menolong, menutup pintu pada tindakan memutus hubungan silaturrahmi sesama manusia, memuliakan kerja, serta tidak merugikan orang-orang yang sedang mengalami kesusahan.

5. Allah dan Rosul melaknat siapapun yang ikut terlibat di dalam praktek tersebut tanpa kecuali.

6. Konteks perilaku riba yang dilakukan masyarakat saat ini antara lain berupa transaksi perbankan terutama perbankan konvensional, transaksi asuransi, transaksi jual beli secara kredit, dan masih banyak lagi.

\section{DAFTAR PUSTAKA}

Departemen Agama RI., Alqur'an dan Terjemahan, Semarang: PT. Toha Putra Semarang.

Fauzan (-al), Saleh, Fiqh Sehari-hari, Cetakan ke-1, Jakarta: Gema Insani, 2006

Kementerian Agama, Terjemahan Tafsir Perkata, Cetakan ke-1, Bandung: Sygma, 2010

Maulan, Riska, Dahsyatnya Riba: Bunga Bank dan Riba, Jakarta: Majelis Ta'lim Wirausaha, 2016

Sabiq, Sayyid, Fiqh Sunnah, Cetakan ke-1, Jakarta: Tinta Abadi Gemilang, 2013

Suhendi, Hendi, Fiqh Mu'amalah, Jakarta: Raja Grafindo Persada, 2007 